Hawse, S., \& Wood Leigh, N. (2019). Designing workplace induction programs to support the transition of new-career engineers to practice. Higher Education, Skills and Work-Based Learning, 9(1), 18-29. doi:10.1108/HESWBL-02-2018-0014

\title{
Designing workplace induction programs to support the transition of new-career engineers to practice
}

\section{Purpose}

The focus of this paper is on transition of engineering graduates to work. It asks: "What approaches and enabling activities can organisational induction programs use to support successful transition to practice for new-career engineers?”

\section{Design/methodology/approach}

This paper is grounded in literature review; it discusses central themes in the literature relating to transition to the workplace for engineering graduates. These include: skills required for the workplace; challenging factors in the transition to workplace; and, disciplinary socialisation.

\section{Findings}

There is a lack of literature that explores the design of workplace induction programs to assist novice engineers transition to professional work. An emerging topic in this literature is educational institution and employing organisation coproduction of induction and transition to work programs.

\section{Originality/value}

Much of the focus of literature relating to transition to work programs is from higher educational programs rather than from the viewpoint of the workplace. This review contributes to knowledge relating to the transition to work for earlycareer engineers from the perspective of workplace development programs.

\section{Keywords}

becoming professional; engineering professionalisation; transition to work; workplace development programs 


\section{Introduction}

This paper investigates literature relating to 'becoming a professional' from the perspective of workplace development programs for early-career engineers. Informed by a scoping review of the literature (Petticrew \& Roberts, 2006), the paper asks: "What approaches and enabling activities can organisational induction programs use to support successful transition to practice for new-career engineers?” It discusses research relating to becoming a professional from the perspective of workplace development programs for early-career engineers. This discussion focuses on the expectations of the workplace, and general or more socially-oriented skills versus engineering skills. The literature incorporates how professional identities are forged, emerging skills development models, and the texts of engineering practice which may be leveraged in induction and development programs to support transition to work.

Engineering is a 'bridging discipline' that brings together other domains beyond the technical. It has many publics, and engineering work is inherently practical, interactive, and multifaceted. On graduation, engineers become practitioners. The transition to work is therefore highly complex and critical for engineering graduates. Degree courses provide the intellectual and scientific foundations of their discipline and emphasise the fundamentals of engineering principles and analysis. There is thus an argument that traditional university curricula develop 'expert students’ or engineering researchers, rather than novice engineers. (Crawley, C., Malmqvist, \& Brodeur, 2008; Reid, Abrandt Dahlgren, Dahlgren, \& Petocz, 2011). Vest (2007) summarises this as: "we educate and train the men and women who drive technological change, but we sometimes forget that they must work in a developing social, economic, and political context” (online). 


\section{Review approach}

Following a scoping review of the literature, the methodology for this inquiry combines systematic and traditional literature review, providing for exploration of key themes identified in the scoping review (Petticrew, 2001; Petticrew \& Roberts, 2006). The review method comprised a database search using the term "engineers transition to the workplace”. Search parameters were restricted to results from 2000 to 2017; the disciplines of Business and Economics, Education, Engineering; peer-reviewed articles, books, theses, conference proceeding; and, the subject keywords from Business; Engineering Education; Higher Education; Learning; Organizational Behaviour. Search parameters returned approximately 1,300 results. The literature includes qualitative and quantitative studies. Key topics include skills required for the workplace; challenging factors in the transition to workplace; and disciplinary socialisation. The review literature is framed through discussion of these themes.

\section{Aligning skills with industry and social need}

Transferrable versus discipline-specific skills, philosophies of knowledge and practice, and the process of becoming a professional anchor transition to work research. Capabilities required for the future workplace encompass critical thinking, creativity, curiosity, and communication skills (Torii \& O’Connell, 2017; World Economic Forum, 2016). Social and economic forces encourage innovation, and the need to apply, review, and extend existing knowledge to new domain boundaries and applications. This emphasises the ability of graduate engineers to make judgments, create solutions, and communicate results. The Motorola Corporation reveals that:

We generally try to determine what an individual knows, how an individual can contribute, the perspective an individual brings to us, and how well the individual fits into the culture of our organisation. ... We want deep technical expertise, but 
that expertise must have a context, and the individual needs to be able to work with others (cited in Crawley, Malmqvist, Östlund, Brodeur, \& Edström, 2014, p. 18).

Employability requires broad and deep skills that are socially constituted. For engineering graduates, this entails science and engineering fundamentals, working knowledge of engineering practice, and awareness of how engineers contribute to society. (Vest, 2014) highlights that challenges for novice engineers are to develop awareness and understanding in business processes, product development and manufacturing. This knowledge requires foundational capacity in conceiving, designing, implementing, and operating complex engineering systems. Sustainable development, and the need to live and work as global citizens increasingly background this skill set.

\section{The capabilities required for engineering work}

To be conversant in a field marks understanding of what it is those who work in the field do (Johnson, Watson, Delahunty, McSwiggen, \& Smith, 2011). Instructional methods such as problem based learning (PBL), project based learning (PBL), and practice-oriented learning frameworks like the Conceive, Design, Implement, Operate (CDIO) initiative align with the practical and situational knowledge of professional activity and address tensions between academia and industry (Kamstrup, 2016). CDIO incorporates industry-identified gaps and accrediting body expectations in the practice areas of: (1) disciplinary knowledge and reasoning, (2) personal and professional skills and attributes, (3) interpersonal skills of teamwork and communication, and (4) developing new knowledge through the process of conceiving, designing, implementing, and operating systems in business, social and environmental contexts. CDIO harmonises with related efforts such as the Tuning Process, which identifies three broad knowledge domains: 
- Instrumental—cognitive, methodological, technological, and linguistic abilities

- Interpersonal—individual abilities including social skills such as interaction and cooperation

- Systemic —abilities and skills which combine understanding and knowledge, and which leverage prior learning and experience (Tuning, 2000, online).

Tuning is a European higher education initiative to align or 'tune' student, tertiary institution, and employer reference points. Its aim is to achieve common understanding across a range of disciplines and key stakeholder groups for the purposes of increasing employability (Gonzélez \& Wagenaar, 2003). Figure 1, adapted from Carvalho (2008, p. 11), summarises how employers, graduates, and academics interpret the skills required for engineering.

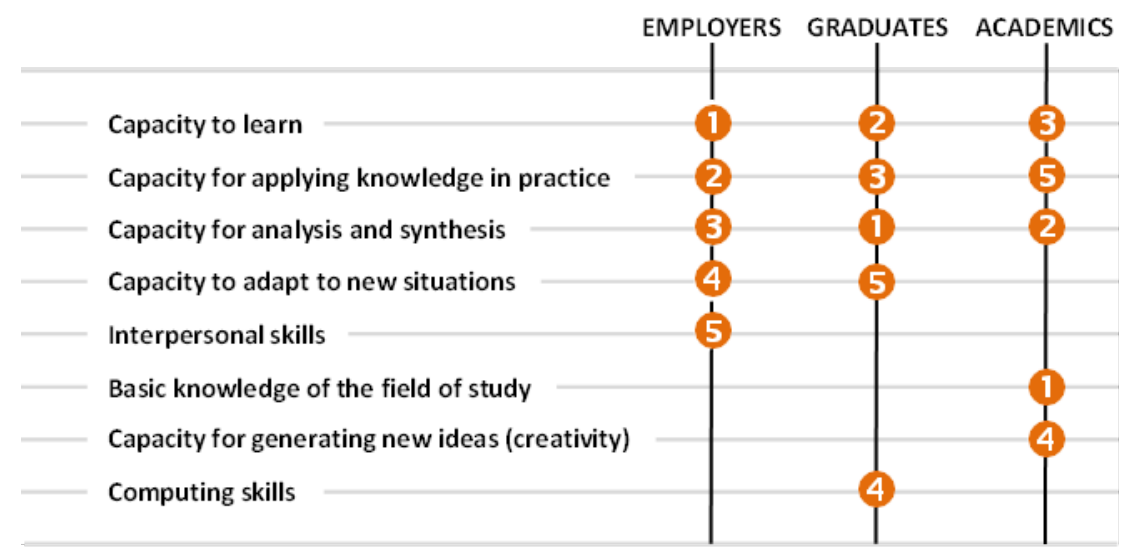

Figure 1. Top five capabilities required for engineering

Employers emphasise practical knowledge application and systemic or 'combinatory' knowledge. Beckett (2008) views this as 'holistic competence', which he associates with professional judgement, or judgements-in-context, and which are developed as part of engaging in work activities. 


\section{Becoming a professional}

There are numerous definitions and interpretations of the complex notions of ‘capability’ and ‘competence’. Alberts and McIntire (2014) observe that workforce effectiveness relies on the two characteristics of competence and readiness. Competence reflects understanding and the ability to apply a given skill. It must be partnered with work readiness to perform job tasks successfully in real-world work environments. Alberts and McIntire (2014) distinguish competency from workforce readiness as: Competence is the sufficient mastery of the knowledge, skills, and abilities—or competencies — needed to perform a given task; whereas, readiness is the ability to apply a set of competencies required to perform a job task with acceptable proficiency. The active and ‘combinatory’ knowledge highlighted by Carvalho (2008) and Beckett (2008) as underpinning effective workplace skills is emphasised by Baytiyeh and Naja (2012). From discussions with professional engineers, Baytiyeh and Naja (2012) note that "the transition from student to an employee is not well understood" (p. 4). Engineering students typically complete a highly structured curriculum. While this ensures that graduates possess the technical knowledge require to begin a career in engineering, it does not accommodate the highly unstructured work environment and multidimensional tasks undertaken by professional engineers. Increasingly, these tasks and the capabilities they require extend beyond the traditionally technical domains of engineering. Huff (2014) for example, explores the development of engineering identity from higher education to the workplace. He finds that the dominant view of engineering as a technical space, where social and political issues are often seen as tangential to the 'real work of engineering' is a view that is often fostered through the undergraduate engineering curriculum. This has broad-reaching implication for what it means to be a professional, with potential impact on further education, apprenticeships, and technical 
and professional education and training.

\section{Acquiring a professional identity}

Professional socialisation is "the process of learning a professional role and emerging as a member of an occupational culture” (Melrose, Miller, Gordon, \& Janzen, 2012, p. 2). It links the worldview specific to disciplines with a professional sense of self. Socialisation is also a means by which we acquire the knowledge, skills, and disposition that enable us to become members of a profession. Johri (2012) points out that in professions where technical competence is highly valued, the challenge for developmental programs is to identify "what newcomers do as they socialise and what this participation means to them” (p. 250). (Sheppard, Macatangay, Colby, \& Sullivan, 2009) leverage the notion of a 'spiral' curriculum first put forward by (Bruner, 1960) to propose an integrated, networked model that interrelates engineering knowledge with “contextual knowledge; competencies of practice, laboratory, and design experiences are integrated into the whole, as are professionalism and ethics” (p. 191). Similarly,

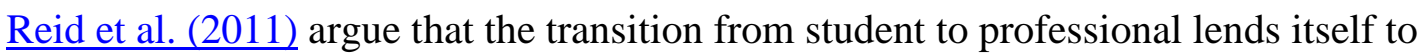
models of professional formation that interpret how contemporary work discourses, and discipline knowledge and professional dispositions interact and influence the development of professional identities. For Scanlon (2011), the journey to becoming a professional is characterised by the iterative formative of a professional identity, or ‘continual becoming', as we shape, reshape and refine our professional selves:

“Becoming” as a metaphor emphasises that learning, practice, and dispositional development are ongoing, and are never completed” (p. 8). This highlights the ongoing nature of learning, and directs attention towards programs that align learning, practice and development. 
In an early developmental study of changes in student understanding, (Perry, 1970) proposes a four-stage evolutionary journey of intellectual and personal development that progresses from (1) accumulating rudimentary facts based on the authority of experts, to (2) perceiving diversity of opinion, through to (3) acknowledging that context and frames of reference underpin these diverse viewpoints, and ultimately to (4) holding one’s own opinions. Systemic knowledge characterises this latter stage, which integrates information and knowledge learned from others with personal experience and reflection (Beckett, 2008). Throughout, learners re-orient themselves as they adjust to new understandings and circumstances. Educational and professional development is therefore a continual journey for which key milestones are exposure to the domain, acquisition of domain knowledge, knowledge application, and ultimately and ideally, contribution to one's chosen field (Perry, 1970; Reid et al., 2011; Scanlon, 2011).

Theories of workplace socialisation reinforce developmental journey analogies. Interlinked with the view of professional 'becoming' is the Aristotelian belief that what we do is who we are - that is, practice and disciplinary values create professional personas. For Knorr-Cetina (1999), people working together are cultures whose collective knowledge exists as practice and evolves as a body of knowledge. Feldman and Orlikowski (2011) propose that "central to a practice lens is the belief that social life is an ongoing production and emerges through people’s recurrent actions” (p. 2). Miller and Goodnow (1995) emphasise the centrality of work activity to personal identity creation; they argue that "the concept of practice recognises that the acquisition of knowledge or skill is part of the construction of an identity or a person” (p. 5). Professional identities are thus continually developed and refined based on feedback from peers, mentors, and role models, and this process is deeply social. 
Trevelyan (2009) observes that engineers spend the majority of their time in communication with close associates. He makes the case for learning programs aimed at engineering practice as a social system in which people interact across discipline boundaries, and within the context of broad societal structures. Korte, Sheppard, and Jordan (2008) describe how early-career engineers approach tasks and problem-solving through finding people with useful information and leveraging organisational experience networks. For workplace training and development, this signifies developing programs that foster networks, emphasising collaborative and cross-functional assignments, and providing graduates with authentic job tasks.

\section{Approaches to skills development}

\section{Developmental taxonomies}

The American Society of Civil Engineers' (2008) Body of Knowledge (BoK) outlines “the necessary depth and breadth of knowledge, skills, and attitudes required of an individual entering the practice of civil engineering at the professional level in the 21st century” (p. 8). The ASCE framework comprises foundational, technical, and professional dimensions of knowledge aligned to outcomes or areas of competency. It acknowledges that there are many developmental taxonomies, and that they describe educational or developmental processes: “The purpose of a taxonomy is to break down this overall development process into smaller discernible 'chunks' within which goals can be articulated, metrics of achievement can be constructed, and achievement can be assessed” (p. 87).

Other contributors to theoretical models of development incorporate 'systemic' capabilities that integrate aspects of experience and socialisation into the learning journey. Table 1 summarises these taxonomies. 
Table 1. Key contributors to developmental taxonomies

\begin{tabular}{|c|c|c|c|}
\hline Reference & Key Concepts & Key Variables & Key Contribution \\
\hline (1956) Bloom et al. & $\begin{array}{l}\text { Classification of } \\
\text { learning objectives } \\
\text { divided into three } \\
\text { domains: cognitive, } \\
\text { affective, and } \\
\text { psychomotor, each of } \\
\text { which has a staged } \\
\text { model of acquisition }\end{array}$ & $\begin{array}{l}\text { Cognitive- } \\
\text { knowing/head } \\
\text { (knowledge) } \\
\text { Affective- } \\
\text { feeling/heart (attitude) } \\
\text { Psychomotor- } \\
\text { doing/hands (skills) }\end{array}$ & $\begin{array}{l}\text { Conceptual framework } \\
\text { for curriculum } \\
\text { development/assessme } \\
\text { nt } \\
\text { Provides verbs for } \\
\text { defining objectives }\end{array}$ \\
\hline (1970) Perry & $\begin{array}{l}\text { Learners go through } \\
\text { staged intellectual } \\
\text { growth }\end{array}$ & $\begin{array}{l}\text { Dualism } \\
\text { Multiplicity } \\
\text { Relativism } \\
\text { Commitment }\end{array}$ & $\begin{array}{l}\text { Framework for staged } \\
\text { intellectual } \\
\text { development } \\
\text { Reflection is the } \\
\text { transition point } \\
\text { between stages }\end{array}$ \\
\hline $\begin{array}{l}\text { (1979) Steinaker and } \\
\text { Bell }\end{array}$ & $\begin{array}{l}\text { Experiential } \\
\text { Taxonomy } \\
\text { Underpinned by } \\
\text { constructivist thinking } \\
\text { Offers a tool to plan, } \\
\text { sequence, deliver and } \\
\text { evaluate learning. }\end{array}$ & $\begin{array}{l}\text { Exposure } \\
\text { Participation } \\
\text { Identification } \\
\text { Internalisation } \\
\text { Dissemination }\end{array}$ & $\begin{array}{l}\text { Good model for } \\
\text { socialisation into a } \\
\text { profession. } \\
\text { Sequences the learning } \\
\text { act. }\end{array}$ \\
\hline $\begin{array}{l}\text { (1980) Dreyfus and } \\
\text { Dreyfus }\end{array}$ & $\begin{array}{l}\text { Taxonomy of skills } \\
\text { acquisition from } \\
\text { novice to expert. } \\
\text { Concrete experience } \\
\text { plays a paramount } \\
\text { role. }\end{array}$ & $\begin{array}{l}\text { Novice } \\
\text { Competent } \\
\text { Proficient } \\
\text { Expert } \\
\text { Master }\end{array}$ & $\begin{array}{l}\text { Benchmark skills } \\
\text { acquisition model. } \\
\text { Presents five cognitive } \\
\text { and skill changes as } \\
\text { one moves from } \\
\text { novice to expert levels } \\
\text { of mastery. }\end{array}$ \\
\hline (1995) Hoffman et al. & $\begin{array}{l}\text { Moves from no } \\
\text { knowledge of } \\
\text { discipline to mastery. } \\
\text { Comprehensive suite } \\
\text { of activities for } \\
\text { eliciting expertise. }\end{array}$ & $\begin{array}{l}\text { Naiveté } \\
\text { Novice } \\
\text { Initiate } \\
\text { Apprentice } \\
\text { Journeyman } \\
\text { Expert } \\
\text { Master }\end{array}$ & $\begin{array}{l}\text { Explores how experts } \\
\text { are defined. } \\
\text { Practical ideas for } \\
\text { eliciting expertise. } \\
\text { Can be used for } \\
\text { knowledge transfer } \\
\text { and retention } \\
\text { programs. }\end{array}$ \\
\hline $\begin{array}{l}\text { (2001) Anderson and } \\
\text { Krathwohl }\end{array}$ & $\begin{array}{l}\text { Bloom's nouns } \\
\text { become verbs. } \\
\text { Shifts priority of } \\
\text { evaluation and } \\
\text { creativity. }\end{array}$ & $\begin{array}{l}\text { Focus on higher order } \\
\text { cognitive skills, } \\
\text { including creativity }\end{array}$ & $\begin{array}{l}\text { Updates Bloom to } \\
\text { integrate with current } \\
\text { skills and literacies. } \\
\text { Accommodates more } \\
\text { active learning } \\
\text { requirements. }\end{array}$ \\
\hline (2003)Alexander & $\begin{array}{l}\text { Expertise is 'domain } \\
\text { acclimation'. } \\
\text { Characterised by } \\
\text { systematic changes } \\
\text { within and across } \\
\text { stages of development. }\end{array}$ & $\begin{array}{l}\text { Acclimation } \\
\text { Competence } \\
\text { Proficiency/Expertise }\end{array}$ & $\begin{array}{l}\text { Considers interplay of } \\
\text { these elements across } \\
\text { the learning process. } \\
\text { Incorporates breadth } \\
\text { and depth of learning. }\end{array}$ \\
\hline
\end{tabular}

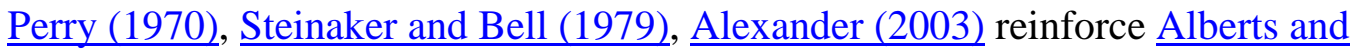

McIntire (2014) that work effectiveness combines mastery of knowledge and skills

within a context that encourages demonstrable capability. Steinaker and Bell's (1979) 
experiential taxonomy is guided by the view that knowledge is constructed or shaped by experience. They propose that learning progresses from initial exposure to a discipline to eventually contributing back to the discipline. Each of these stages of 'exposure, participation, identification, internalisation, and dissemination' is associated with introspection and knowledge processing. Similarly, for Alexander (2003), sharing or contributing knowledge signifies expertise. She notes that, "not only is the knowledge of experts broad and deep, but the experts are also contributing new knowledge to the domain” (p. 12).

Participating as a member of a disciplinary community

Vest (2014) underscores the importance of authentic and enabling learning environments:

Students, for example, are driven by passion, curiosity, engagement, and dreams. Although we cannot know exactly what they should be taught, we focus on the environment and context in which they learn, and the forces, ideas, inspirations, and empowering authentic situations to which they are exposed (Vest, 2014, p. iv).

The World Economic Forum (2016) similarly emphasises the role of social and emotional learning (SEL) skills, including collaboration, communication, and problemsolving. Bransford (2007) suggests that focusing on the context of how one learns, encourages resilience and develops behaviours that are receptive to uncertainty. This helps students learn about themselves as thinkers and as problem-solvers. It assists them to “develop an identity as a lifelong learner rather than as an expert who is supposed to know all the answers” (p. 3). Fink’s (2003) taxonomy of significant learning addresses the call for important kinds of learning that do not emerge easily from traditional learning models. He proposes six transformational learning dimensions: (1) acquiring foundational knowledge or facts and ideas, (2) applying knowledge through various 
types of thinking and activities, (3) integrating ideas and seeing connections between things, (4) understanding the human dimension of knowledge by relating it to self and others, (5) becoming engaged and involved as a result of learning, and (6) becoming self-directed learners through the process of learning how to learn.

The UK Institution of Civil Engineers (ICE) Competency Framework for Professional Development sets out the knowledge, skills, and attitudes that are recognised and valued by the institution. Like the ASCE BoK, the ICE framework identifies the need for more holistic skills underpinned by a foundation of technical capability. It sees engineers through the broad lenses of self, citizenship, and the context of practice to "help engender those competencies attributed to a well-rounded practitioner at the heart of society” Institution of Civil Engineers $(2011$, p. 3). The ASCE reaches back into the curriculum and frames the capabilities required of graduates. ICE focuses on deepening and extending this foundational capability in practice. Behavioural, leadership, management and industry knowledge, and applied skills are "gained through experience and interaction and are cultivated, matured, and honed through continuing professional development” Institution of Civil Engineers (2011, p. 3).

\section{Opportunities for the workplace}

"The transition from university to an engineering career is highly complex and critically important for graduating engineers” (Baytiyeh \& Naja, 2012, p. 12). Professional engineers work in increasingly unstructured environments and perform multidimensional tasks. Engineering work is also influenced by transactional 'hidden' elements, including awareness of human factors, socio-political influences, and environmental and economic considerations (Finkel \& King, 2013; Trevelyan, 2010). This highlights the ability of graduate engineers to make judgments, create solutions, to 
reflect on their decisions and solutions, and to communicate results. It stresses the need for organisations to provide guided and authentic activities that develop these capabilities in new engineers.

“The process of learning a complex practice such as engineering necessarily shapes the perception, imagination, and deportment of anyone who undergoes it” (Sheppard et al., 2009, p. 188). They present five guiding principles for engineering education, which are extensible as a design manifesto for workplace learning programs:

- Engineering work is inherently interactive and complex;

- Formulating problems and solving problems are interdependent activities;

- Engineering has many publics;

- Engineering incorporates many domains beyond the technical;

- Engineers affect the world (Sheppard et al., 2009, pp. 175-176).

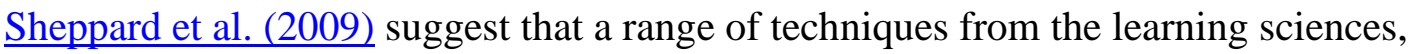
such as mentoring, cognitive apprenticeship (modelling the processes that experts use to handle complex tasks), and scaffolding (guided 'stretch' tasks) can help to impart and to make visible the experience and knowledge of engineering practice. Solving complex workplace problems with conflicting goals, encouraging diverse and innovative ways to achieve solutions, and managing non-engineering constraints and success measures are activities that can be used to support the transition of early career engineers to professional practice (Jonassen, Strobel, \& Lee, 2006).

For Hays and Clements (2012) and Eraut (2007), work-related learning is with, through, and in work activities. Workplace induction and development programs for graduates typically blend practical on-the-job experience with academic or formal learning activities. These programs are tailored to provide personal and professional 
skills required for the program type and the knowledge needs of participants. Program elements include: on-campus residential studies; job rotations through projects and teams; discipline-specific site visits; work-based projects and stretch tasks; buddy and mentoring programs; networking / industry events; and defined career pathways that include further degrees, professional networks, and chartership (Arup, 2017; Exon, 2017; RMS, 2017). Learning incorporates guidance from colleagues and work-group peers, and can involve structured learning and knowledge transfer activities, such as job shadowing. To respond to expectations of both graduates and of corporate members, the Australasian Institute of Mining and Metallurgy (AusIMM) Graduate Program Best Practice Guidelines outlines an industry standard for graduate induction and professional development (AusIMM, 2017). Its graduate program recommendations conform to the 70:20:10 model of many workplace development programs, adapted to the mining industry. The 70:20:10 model suggests the optimum balance for professional learning is: 70 percent for informal, practical and experiential 'stretch' tasks; 20 percent for coaching, mentoring and developing through others; and, 10 percent for formal learning, training, and structured courses (Kajewski \& Madsen, 2012). The AusIMM guidelines combine general elements appropriate to all industry graduate development programs, and discipline-specific elements to shape graduate development program for individual minerals professions. The guidelines are framed as an agreement, with the program comprised of mentoring, being entrusted with meaningful responsibilities, and formal training. Kramer-Simpson, Newmark, and Dyke Ford (2015) provide a community of practice alternative to the 70:20:10 model. From student feedback, observation, text analysis, and transcribed interview data on student participation in client projects as preparation for internships, they determine that "client projects serve as an important first step for learning and particularly for becoming part of a community 
of practice by recognising an organisation's values and goals” (p. 107). While acknowledging their results are limited to higher education work-integrated learning activities, and that including client perspectives and success measures would strengthen their results, Kramer-Simpson et al. (2015) observe that participating in client projects supports the transition from newcomer to an experienced member of a community. Client projects also serve to "make knowledge transparent” (p. 121) and enable transfer of this knowing to the workplace.

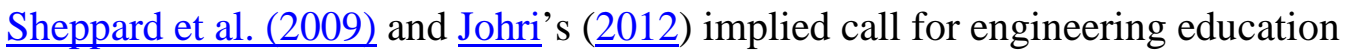
to yield practical or 'usable knowledge', is reiterated by Johnson et al. (2011), who approach professional activities via the texts of a discipline. They adopt Smagorinsky’s expansive interpretation of text, which encompasses "any configuration of signs that provide a potential for meaning” (Smagorinsky, 2001, p. 137). For Artemeva (2009), these texts or domain-specific genres assist novice engineers to transition from the university context to workplace communities of practice. Engineering texts or meaningmaking activities include interpreting client requirements, designing and evaluating technically and commercially effective solutions, and accessing the knowledge and experience of colleagues and related disciplines . Table 2 lists activities that correspond to engineering practice.

Table 2. Conceive Design Implement Operate (CDIO) (Crawley et al., 2014, p. 26)

\begin{tabular}{|l|l|}
\hline Conceive & $\begin{array}{l}\text { Defining customer needs, considering technology, enterprise strategy and } \\
\text { regulations, and developing conceptual, technical, and business plans. }\end{array}$ \\
\hline Design & $\begin{array}{l}\text { Creating the detailed information description of the design; the plans, drawings, and } \\
\text { algorithms that describe the system to be implemented. }\end{array}$ \\
\hline Implement & $\begin{array}{l}\text { Transforming the design into the product, process, or system, including hardware } \\
\text { manufacturing, software coding, testing, and validation. }\end{array}$ \\
\hline Operate & $\begin{array}{l}\text { Using the implemented product, process, or system to deliver the intended value, } \\
\text { including maintaining, evolving, recycling, and retiring the system. }\end{array}$ \\
\hline
\end{tabular}

\section{Conclusion}

Engineering has become an expansive discipline. Its boundaries are progressively 
intersecting those of other disciplines and knowledge areas in a 'landscape of practice' (Trevelyan, 2014). As the scope of their discipline expands, the knowledge needs of engineers increases. This requires both higher education and the workplace to focus on learning design that integrates engineering knowledge with the technical, social, and political context of engineering work. For the workplace, professional learning in the form of shared activity connects formal education bodies of knowledge (curricula) with the knowledgeability of practice (social- and context-based experience). This shared activity orients 'the real work of engineering' away from an exclusively technical domain, and towards developing technical solutions in a multidisciplinary, social, ethical, and political context. The literature provides theoretical models of cognitive development and professional socialisation, and practical examples of good practice in induction programs. These include program design that incorporates peer groups and workplace communities of practice. Mentoring, induction peer groups, participating in professional networks, workgroup activities, and stretch tasks to develop technical, professional, and leadership capabilities utilise the increasingly unstructured work environment and complex tasks undertaken by professional engineers. The literature suggests there are opportunities for the workplace to further incorporate individual and workgroup reflection and continuous improvement practices. For new graduates, this supports the development of 'systemic' or 'holistic competence' which is foundational to professional judgement and the ability to adapt skills and professional behaviours as needed. There are also opportunities for workplace induction programs to leverage the conventions and 'texts' of engineering work to support the transition from formal education to workplace project teams and communities of practice. These texts or meaning-making activities include accessing the knowledge and experience of colleagues, navigating multidisciplinary projects, interpreting client requirements, and 
participating in the development of technically, commercially, and socially viable outcomes. From the literature, implications for further research into programs that support the transition to professional work include specific focus on shared problem solving and the development of professional judgement; cross-disciplinary work practices and modes of communication; and, centralising the texts or meaning-making artefacts of engineering practice in induction programs. 


\section{References}

Alberts, C. J., \& McIntire, D. (2014). A Systematic approach for assessing workforce readiness. Technical Report. CERT Division. Carnegie Mellon University. Software Engineering Institute.

Alexander, P. A. (2003). The development of expertise: The journey from acclimation to proficiency. Educational Researcher, 32(8), 10-14.

Anderson, L. W., \& Krathwohl, D. R. (Eds.). (2001). A taxonomy for learning, teaching, and assessing: A revision of Bloom's taxonomy of educational objectives. Boston, MA: Allyn \& Bacon (Pearson Education Group)

Artemeva, N. (2009). Stories of becoming: A study of novice engineers learning genres of their profession. Genre in a changing world, 158-178.

Arup. (2017). Graduate program. Retrieved from

https://www.arup.com/careers/graduates-and-interns/australasia/graduateprogram

ASCE. (2008). Civil engineering body of knowledge for the 21st century: Preparing the civil engineer for the future. Retrieved from

http://www.asce.org/uploadedFiles/Education_and_Careers/Body_of_Knowledg e/Content_Pieces/body-of-knowledge.pdf

AusIMM. (2017). Graduate program best practice guidelines. Australasian Institute of Mining and Metallurgy. Carlton, Victoria Australia. Retrieved from http://www.ausimm.com.au/content/docs/ausimm_graduate_guidelines.pdf

Baytiyeh, H., \& Naja, M. (2012). Identifying the challenging factors in the transition from colleges of engineering to employment. European Journal of Engineering Education, 37(1), 3-14.

Beckett, D. (2008). Holistic competence: Putting judgements first. Asia Pacific Education Review, 9(1), 21-30.

Bloom, B. S., Engelhart, M. D., Furst, E. J., Hill, W. H., \& Krathwohl, D. R. (1956). Taxonomy of educational objectives. N.Y.: Longmans, Green.

Bransford, J. (2007). Preparing people for rapidly changing environments. Journal of Engineering Education, 96(1), 1-3.

Bruner, J. S. (1960). The process of education. Cambridge: Cambridge : Harvard University Press.

Carvalho, J. (2008). International aspects of Bologna: The Tuning Project. Paper presented at the BALANCE - Bologna: A long-term approach to new certification in Europe, University of Turku, Finland. http://www.coimbragroup.eu/balance/Docs/turku/International\%20Aspect\%20of\%20Bologna\%20Pr ocess\%20-Tuning.ppt.

Crawley, E. F., C., J., Malmqvist, J., \& Brodeur, D. R. (2008). The context in engineering education. Paper presented at the 4th International CDIO Conference, Hogeschool Gent, Gent, Belgium, . http://www.cdio.org/files/document/file/m1-crawley2008.pdf

Crawley, E. F., Malmqvist, J., Östlund, S., Brodeur, D. R., \& Edström, K. (2014). Rethinking engineering education: The CDIO approach (2nd ed.). Heidelberg, Germany: Springer.

Dreyfus, S. E., \& Dreyfus, H. L. (1980). A five-stage model of the mental activities involved in directed skill acquisition. Monograph. Operations Research Center. 
California University Berkeley. Retrieved from http://www.dtic.mil/cgibin/GetTRDoc?AD=ADA084551\&Location=U2\&doc=GetTRDoc.pdf

Eraut, M. (2007). Learning from other people in the workplace. Oxford Review of Education, 33(4), 403-422.

Exon. (2017). BEng civil engineering site management. Engineering. University of Exeter. Retrieved from http://www.exeter.ac.uk/undergraduate/degrees/engineering/civil-engineering/

Feldman, M. S., \& Orlikowski, W. J. (2011). Theorizing practice and practicing theory. Organization Science, 22(2011), 1240-1253.

Fink, L. D. (2003). Creating significant learning experiences: An integrated approach to designing college courses. San Francisco: Jossey-Bass.

Finkel, A., \& King, R. (2013). Innovative approaches to engineering education. Paper presented at the CAETS, International Council of Academies of Engineering and Technological Sciences, Budapest, Hungary.

Gonzélez, J., \& Wagenaar, R. (2003). Tuning educational structures in Europe. Final report. Phase one. Universidad de Deusto: Deusto. Retrieved from http://www.bolognakg.net/doc/Tuning_phase1_full_document.pdf

Hays, J., \& Clements, M. (2012, 20-22 June, 2102). Transition-bridging the gap between study and work. Paper presented at the Proceedings of the 9th International Conference on Cooperative \& Work-Integrated Education, Where East meets West and Theory meets Practice, Istanbul, Turkey.

Hoffman, R. R., Shadbolt, N. R., Burton, A. M., \& Klein, G. (1995). Eliciting knowledge from experts: A methodological analysis. Organizational Behavior and Human Decision Processes, 62(2), 129-158.

Huff, J. L. (2014). Psychological journeys of engineering identity from school to the workplace: How students become engineers among other forms of self. (PhD), Purdue University,

Institution of Civil Engineers. (2011). Competency framework for professional development. Institution of Civil Engineers (ICE). Westminster, London. Retrieved from http://www.gedcouncil.org/sites/default/files/ICE-CompetencyFramework.pdf

Johnson, H., Watson, P. A., Delahunty, T., McSwiggen, P., \& Smith, T. (2011). What it is they do? Differentiating knowledge and literacy practices across content disciplines. Journal of Adolescent \& Adult Literacy, 55(2), 100-109.

Johri, A. (2012). Learning to demo: The sociomateriality of newcomer participation in engineering research practices. Engineering Studies, 4(3), 249-269.

Jonassen, D. H., Strobel, J., \& Lee, C. B. (2006). Everyday problem solving in engineering: Lessons for engineering educators. Journal of Engineering Education, 95(2), 139-151. doi:10.1002/j.2168-9830.2006.tb00885.x

Kajewski, K., \& Madsen, V. (2012). Demystifying 70:20:10 white paper. Retrieved from http://deakinprime.com/media/47821/002978_dpw_70-2010wp_v01_fa.pdf

Kamstrup, A. K. (2016). CDIO Enacted: Tracing the multiplicity of an initiative in engineering education. In U. Jørgensen \& S. Brodersen (Eds.), Engineering professionalism: Engineering practices in work and education (pp. 105-123). Rotterdam: SensePublishers.

Knorr-Cetina, K. (1999). Epistemic cultures: How the sciences make knowledge. Harvard: Harvard University Press. 
Korte, R., Sheppard, S., \& Jordan, W. (2008). A qualitative study of the early work experiences of recent graduates in engineering. Paper presented at the American Society for Engineering Education, June 22-26 2008, Pittsburgh, PA.

Kramer-Simpson, E., Newmark, J., \& Dyke Ford, J. (2015). Learning beyond the classroom and textbook: Client projects' role in helping students transition from school to work. Professional Communication, IEEE Transactions on, 58(1), 106-122. doi:10.1109/TPC.2015.2423352

Melrose, S., Miller, J., Gordon, K., \& Janzen, K. J. (2012). Becoming socialized into a new professional role: LPN to BN student nurses' experiences with legitimation. Nursing Research and Practice, 2012.

Miller, P. J., \& Goodnow, J. J. (1995). Cultural practices: Toward an integration of culture and development. New Directions for Child and Adolescent Development, 1995(67), 5-16.

Perry, W. G., Jr. (1970). Forms of intellectual and ethical development in the college years: A scheme. New York: Holt, Rinehart, and Winston.

Petticrew, M. (2001). Systematic reviews from astronomy to zoology: myths and misconceptions. British Medical Journal, 322(7278), 98-101. doi:10.1136/bmj.322.7278.98

Petticrew, M., \& Roberts, H. (2006). Systematic reviews in the social sciences: A practical guide. Oxford, UK: Blackwell Publishing.

Reid, A., Abrandt Dahlgren, M., Dahlgren, L. O., \& Petocz, P. (2011). From expert student to novice professional (Vol. 99). The Netherlands: Springer.

RMS. (2017). Road designer in training. Employment Services. Roads and Maritme Services. Sydney, NSW, Australia. Retrieved from http://www.rms.nsw.gov.au/about/careers/working-with-us/employmentprograms/road-designer-in-training.html

Scanlon, L. (2011). 'Becoming' a professional. In L. Scanlon (Ed.), "Becoming" a professional (Vol. 16, pp. 13-32). The Netherlands: Springer.

Sheppard, S., Macatangay, K., Colby, A., \& Sullivan, W. M. (2009). Educating engineers: Designing for the future of the field (Vol. 9). San Francisco, CA: Jossey-Bass.

Smagorinsky, P. (2001). If meaning is constructed, what is it made from? Toward a cultural theory of reading. Review of Educational Research, 71(1), 133-169.

Steinaker, N., \& Bell, M. (1979). The experiential taxonomy: A new approach to teaching and learning. New York, NY: Academic Press.

Torii, K., \& O’Connell, M. (2017). Preparing young people for the future of work. Mitchell Institute. Melbourne. Retrieved from http://www.mitchellinstitute.org.au/reports/preparing-young-people-for-thefuture-of-work/

Trevelyan, J. P. (2009). Engineering education requires a better model of engineering practice. Paper presented at the Research in Engineering Education Symposium 2009, Palm Cove, QLD, Australia.

Trevelyan, J. P. (2010). Reconstructing engineering from practice. Engineering Studies, 2(3), 175-195.

Trevelyan, J. P. (2014). The making of an expert engineer. Leiden, The Netherlands: CRC Press.

Tuning. (2000). Tuning educational structures in Europe. Retrieved from http://www.unideusto.org/tuningeu/ 
Vest, C. M. (2007). Educating engineers for 2020 and beyond. National Academy of Engineering, Grand Challenges Blog. Retrieved from http://www.engineeringchallenges.org/14373/GrandChallengesBlog/7639.aspx

Vest, C. M. (2014). Forward: Educating engineers for 2020 and beyond. In E. F. Crawley, J. Malmqvist, S. Östlund, D. R. Brodeur, \& K. Edström (Eds.), Rethinking engineering education: The CDIO approach (2nd ed.). Heidelberg, Germany: Springer.

World Economic Forum. (2016). New vision for education: Fostering social and emotional learning through technology. Retrieved from https://www.weforum.org/reports/new-vision-for-education-fostering-socialand-emotional-learning-through-technology 